\title{
PrevalênCia de marcadores Imuno-hematológicos em RecÉm-nascidos AO NASCIMENTO E EM SUAS RESPECTIVAS MÄES E INCIDÊNCIA DE DOENÇA hemolítica nUMa maternidade de Säo PaUlo
}

\author{
Marco Antonio Cianciarullo*, Maria Esther Jurfest Ceccon, flávio Adolfo Costa Vaz \\ Trabalho realizado no Hospital e Maternidade Santa Joana e Instituto da Criança do Hospital das Clínicas da FMUSP, São Paulo, SP
}

RESUMO: A introdução da imunoglobulina anti-D diminuiu a incidência da doença hemolítica neonatal por isoimunização $R h$, porém persiste este diagnóstico por outros anticorpos mais raros e 0 avanço tecnológico tornou possível a detecção destes anticorpos.

OBjetivos. Verificar a prevalência de marcadores imuno-hematológicos, representados pelos testes de Coombs indireto, direto e de eluição com identificação do anticorpo detectado; incidência de doença hemolítica e de tratamento entre os recém-nascidos sensibilizados.

Métodos. Estudo do tipo Coorte retrospectiva, de janeiro de 1996 a julho de 1998, consistiu na descrição da análise dos perfis imuno-hematológicos de 1698 pares de mães e recém-nascidos como fator de risco para doença hemolítica, subdivididos de acordo com os marcadores. A metodologia empregada para identificação dos marcadores foi 0 da microplaca com hemácias de triagem, soro antiglobulina humana e gel centrifugação. Para tipagens e fenotipagens utilizou-se o método de microplaca com soros monoclonais. Para 0 estudo da incidência e seguimento neonatal foram realizadas bilirrubinas totais e frações, por método enzimático colorímetro, hemoglobina e hematócrito, automatizado e reticulócitos, por coloração supra vital, azul cresil brilhante e leitura por microscopia óptica.
Resultados. A prevalência de marcadores imuno-hematológicos associados à doença hemolítica foi de $9,07 \%$. Por grupos estratificados obtivemos no grupo com Coombs indireto (grupo I) 0,43\%; no grupo com Coombs direto (grupo D), $4,10 \%$ e no grupo com eluição (grupo E) 4,53\%. A incidência de doença hemolítica no estudo foi de $36,23 \%$. Quando estratificada por grupos, obtivemos no grupo I, $33,56 \%$, no grupo D, $44,43 \%$ e no grupo $E, 29,24 \%$. 0 tratamento com fototerapia foi necessário em $36,23 \%$ dos RN, sendo maior sua indicação no grupo $D$ e a exsangüíneotransfusão foi necessária em $0,88 \%$ dos RN, sendo maior sua indicação no grupo $\mathrm{I}$.

Conclusões. 0 grupo I, onde se concentram as incompatibilidades $\mathrm{Rh}$, apresentou maior incidência de doença hemolítica e maior necessidade de tratamento com exsangüíneotransfusão, o que mostra ainda a gravidade deste sistema em nosso meio. 0 grupo $D$, onde se concentram as incompatibilidades $A B O$, apresentou maior incidência de doença hemolítica e tratamento com fototerapia e menor necessidade de exsangüíneotransfusão.

UNITERMOS: Icterícia neonatal/epidemiologia. Marcadores biológicos. Fototerapia. Transfusão total. Icterícia neonatal/terapia. Teste de Coombs/métodos.

\section{INTRODUÇÃO}

Os avanços na assistência obstétrica têm mudado o perfil da isoimunização $\mathrm{Rh}$, porém continua havendo quadros hemolíticos com hiperbilirrubinemias significativas que podem levar a "kernicterus" e que na maioria dos serviços neonatais ficam sem diagnóstico. $\mathrm{Na}$ atualidade, utilizando técnicas mais sensíveis, consegue-se diagnosticar anticorpos raros e outras doenças potencialmente hemolíticas.

Mas, apesar dos avanços, a hemólise no recém-nascidoé de difícil documentação, porque a hiperbilirrubinemia indireta é comume os níveis de hemoglobina são estáveis durante

* Correspondência:

Avenida Novede Julho, 5739/82

Jardim Europa-Telefone:(11)3168-3242 a primeira semana de vida. Neste contexto, 0 parâmetro mais confiável é o número de reticulócitos, que embora alto no recém-nascido $(4,1 \%$ a $6,3 \%)$ se normaliza ao terceiro dia devida. Ea persistência desta reticulocitose é compatível com o processo hemolítico, embora reticulopenia não o exclua.

Acreditamos que para realizar um diagnóstico preciso de doença hemolítica no RNé necessária a realização de testes que detectem anticorpos antieritrocitários como o teste de Coombs indireto, direto e o teste de eluição.

Os objetivos deste estudo foram: verificara prevalência de anticorpos eritrocitários maternos imunodetectáveis na população estudada e relacioná-los com a evolução clínica dos recémnascidos quanto à manifestação de doença hemolíticaneonatal enecessidade de tratamento comfototerapiae/ou exsangüíneotransfusão.

\section{Métodos}

Foi realizado estudo do tipo Coorte retrospectiva, de $1^{\circ}$ de janeiro de 1996 a $1^{\circ}$ de julho de 1998, e consistiu na descrição da análise dos perfis imuno-hematológicos de 1698 pares de mães e recém-nascidos, analisando-os como fator de risco para doença hemolítica neonatal. No delineamento do estudo foram realizadas 35138 fenotipagens maternas e 35429 fenotipagens neonatais (incluindo gemelares) eselecionados (critérios de inclusão) os recém-nascidos expostos a anticorpos maternos com passagem transplacentária (através de exames de triagem de sensibilização materno-fetal) e com potencialidade de desenvolvimento de doença hemolítica neonatal e divididos em três grupos. Grupo I: com inclusão universal de I49 recém-nascidos cujas mães apresentaram tes- 
te de Coombs indireto positivo e anticorpos associados à doença hemolítica neonatal. Este grup o foi ainda subdividido em dois subgrupos denominados Grupo I-A (Cl+CD+): com 83 recém-nascidos, quando estes apresentaram teste de Coombs direto positivo e, Grupo I-B (Cl+CD-) com 66 recém-nascidos, quando o teste de Coombs direto foi negativo. GrupoD: com 736 recém-nascidos com teste de Coombs direto positivo de mães com teste de Coombs indireto negativo, representando metade da amostra aleatória de mães e recémnascidos nesta condição. Grupo E: com 807 recém-nascidos com teste de Coombs direto negativo e teste de eluição positivo de mães com teste de Coombs indireto negativos, como mesmo sistema amostral adotado no grupo $D$.

Para a realização dos perfis imuno-hematológicos maternos e dos recém-nascidos foram colhidos $7 \mathrm{ml}$ de sangue por via periférica e $5 \mathrm{ml}$ de sangue do cordão umbilical ou de vasos fetais da placenta.

O estudo imuno-hematológico e as dosagens laboratoriais citados a seguir foram realizados, respectivamente, no Banco de Sangue e no Laboratório do Hospital e Maternidade Santa Joana:

Para o estudo de prevalência fizeram parte dos métodos de diagnósticos: a) Teste de Coombs Direto, pelo método da microplaca com soros antiglobulina humana da GAMMA $®$ Biological Inc. e, se necessário, confirmação por gel-centrifugação com hemácias de triagem da DIAMED-ID Micro TypingSystem. b) Teste de Coombs Indireto, pelo método da microplaca com hemácias de triagem e soro antiglobulina humana da GAMMA® Biological Inc. e, se necessário, com confirmação pelo gel centrifugação com hemácias de triagem da DIAMED-ID Micro Typing System. c) Tipagem ABO / Rh, pelo método de microplaca com soros monoclonais da GAMMA $®$ Biological Inc. e DIAMED-ID Micro Typing System. d) Fenotipagem $\mathbf{R h}$, pelo método de microplacas com soros monoclonais da GAMMA $®$ Biological lnc. e) Sistema Kell, pelo método de microplacas com soros monoclonais da GAMMA® Biological Inc. f) Identificação de Anticorpos imunodetectáveis, pelo método de gel centrifugação(DIAMED-ID Micro Typing System).

Para o estudo de incidência e seguimento dos recém-nascidos fizeram parte os seguintes exames laboratoriais: a) Bilirrubina total e frações, pelo método enzimático colorí- metro, b) Hemoglobina e hematócrito, automatizado (COBAS MICROS), c) Reticulócitos, por coloração supra vital, azul cresil brilhante e leitura por microscopia óptica.

Os resultados foram submetidos à análise estatística através dos testes de qui-quadrado e exato de Fisher com significância de 5\%.

\section{Resultados}

Os resultados são apresentados na forma de tabelas.

\section{Discussão}

A) Prevalência: Aisoimunização materna ocorre por exposição destes antígenos estranhos e como resposta ocorre a formação de anticorpos. Este contato com o sangue fetal pode ser devido a uma transfusão feto-materna fisiológica durante a gestação. Esta ocorre com freqüência que se eleva com o avanço da idade gestacional devido ao aumento da área de superfície placentária, com maior risco de transporte de eritrócitos fetais para a circulação materna. A freqüência de transfusão é de $7 \%$, $16 \%$ e $29 \%$, respectivamente no primeiro, segundo e terceiro trimestre de gestação'.

Processos patológicos, tais como aborto espontâneo, gravidez ectópica, descolamento placentário, trauma abdominal e placenta prévia ou em procedimentos obstétricos onde há ruptura da barreira feto-materna, tais como amostra das vilosidades coriônicas, amniocentese, cordocentese, versão cefálica externa, remoção manual da placenta, cesárea anterior, aborto terapêutico, além da transfusão de hemoderivados autólogos, desencadeiam a isoimunização da gestante e com isso a produção de anticorpos ${ }^{1,2}$. Por outro lado, Murray ${ }^{3}$ et al., em 1983, relatam que as sensibilizações continuam ocorrendo como resultado de doses inadequadas de imunoglobulinas, na falha por não indicação, nos casos de abortos, neomortos e natimortos, como prevenção e tratamento dos erros transfusionais, amniocentese, cordocentese entre outros.

DeVrijer ${ }^{4}$ et al., em 1999, citam a incidência de anticorpos eritrocitários atípicos em multigestas e primigestas com história prévia de transfusão sanguínea. Entre 2204 mulheres multigestas e 188 primigestas foram encontrados 8 I anticorpos atípicos em 65 gestantes ea incidência da doença hemolítica nos seus recém-nascidos foi de $40 \%$.
Em nosso estudo não foi possível resgatar dentro do passado gestacional de todas as gestantes o uso de RHOGAM, transfusões sangüíneas, cesáreas anteriores e/ou amniocentese, cordocentese ou outros procedimentos invasivos que contribuíssem para minimizar ou agravar a síndrome ictérica.

Aincompatibilidade $A B O$ é descrita como de ocorrência quase exclusiva nos casos onde a mãe é do grupo sangüíneo $O$ e o recémnascido, $A$ ou $B$. Este fenômeno curioso é atribuído a produção de anticorpos anti-A e anti-B nestas mães do grupo sangüíneo $O$, cujas classes de imunoglobulina são lgG com passagem transplacentária. As outras mães, de grupo sanguíneo $A$ ou $B$, produzem anticorpos anti-B e anti-A, respectivamente, da classe IgM, sem passagem à barreira placentária ${ }^{5,6}$. Ozoleck ${ }^{7}$ et al., em 1993, em estudo de prevalência de incompatibilidade $A B O$, comparando a positividade do teste de Coombs nos recém-nascidos filhos de mães do grupo sangüíneo $O$ com recém-nascidos de mães $A$ ou B, observaram 4996 recém-nascidos. Destes, observou-se que 760/4996 (I5\%) tinham mães do grupo sangüíneo $0,191 / 4996$ (3,8\%), do grupo A e $152 / 4996$ (3\%), do grupo B. A positividade ao teste de Coombs nos recém-nascidos com mães dos grupos $O$, Ae B foi, respectivamente, $32 \%, 0,52 \%$ e $0 \%$, - que demonstra a raridade da doença hemolítica neonatal nestes pares de mães $\mathrm{e}$ recém-nascidos.

Dos anticorpos detectados no grupo I-A (Tabela I) predominam os do sistema Rhesus, anticorpo anti-D com 58,4\% (63/108) e os anticorpos Rhesus não anti-D (anti-C, anti-c, anti-E, anti-e) com 28,7\% (3I/I08). O sistema $\mathrm{ABO}$ contribuiu com $9,3 \%(10 / 108)$ e os sistemas mais raros (anti-Jka anti-S, anti-Fy $)$, com 3,7\% (4/I08) (Tabela I).

No grupo I-B (Tabela I) predomina os anticorpos do sistema Rhesus, anticorpo antiD com 55,6\% (5/9) e outros anticorpos não anti-D (anti-C, anti-c) com 33,3\% (3/9) totalizando $88,9 \%(8 / 9)$. O sistema ABO contribuiu apenas com um anticorpo, anti-A, II,I\% (I/9) e nenhum anticorpo de sistemas mais raros foi detectado.

A despeito da introdução de imunoglobulina anti-D com redução da mortalidade e morbidade, este estudo mostra ainda que os anticorpos anti-D permanecem os mais importantes, podendo resultar em morbidade 
Tabela I - Anticorpos titulados no estudo de prevalência de marcadores imuno-hematológicos para doença hemolítica neonatal subdivididos em grupos

\begin{tabular}{|c|c|c|c|c|c|}
\hline \multirow{11}{*}{$\Xi$} & Grupos ( $n^{\circ}$ de RN) & Anticorpos titulados & $\mathrm{n}^{\xi}$ & $\%$ & $\%$ dentro de cada grupo \\
\hline & \multirow{9}{*}{$(83 \mathrm{RN})^{+}$} & $\begin{array}{l}\text { A } \\
B\end{array}$ & $\begin{array}{l}7 \\
3\end{array}$ & $\left.\begin{array}{l}6,5 \\
2,8\end{array}\right\}$ & \multirow[t]{3}{*}{9,3} \\
\hline & & C & 12 & $|1| 1$, & \\
\hline & & c & 9 & 8,3 & \\
\hline & & D & 63 & 58,4 & \multirow[t]{3}{*}{87,0} \\
\hline & & $E$ & 9 & 8,3 & \\
\hline & & e & I & 0,9 J & \\
\hline & & jka & I & 0,91 & \multirow{4}{*}{3,7} \\
\hline & & $S$ & 2 & $1,9\}$ & \\
\hline & & Fya & I & 0,9 J & \\
\hline & Total de anticorpos & & 108 & 100 & \\
\hline \multirow{5}{*}{$\underline{\underline{m}}$} & & A & I & $I I, I$ & $\mathrm{II}, \mathrm{I}$ \\
\hline & $(66 \mathrm{RN})^{++}$ & C & I & 11,11 & \multirow{4}{*}{88,9} \\
\hline & & C & 2 & $22,2\}$ & \\
\hline & & D & 5 & 55,6 & \\
\hline & Total de anticorpos & & 9 & 100 & \\
\hline \multirow[t]{3}{*}{0} & (736 RN) & B & 580 & $78,8\}$ & \multirow{3}{*}{100} \\
\hline & & A & 156 & $21,2\}$ & \\
\hline & Total de anticorpos & & 736 & 100 & \\
\hline \multirow{4}{*}{$\boldsymbol{~}$} & & A & 663 & $82,2\}$ & \multirow{4}{*}{$\begin{array}{c}99,9 \\
0,1\end{array}$} \\
\hline & $(807 \mathrm{RN})^{*}$ & B & 143 & $17,7\}$ & \\
\hline & & $E$ & 1 & 0,1 & \\
\hline & Total de anticorpos & & 807 & 100 & \\
\hline
\end{tabular}

${ }^{++} 21$ pacientes com mais de um anticorpo

'Númerodeanticorpos

${ }^{++}$um paciente com dois anticorpos

* Um dos pacientes foi excluído do follow up

por doença hemolítica neonatal. Howard ${ }^{8}$ et al., em 1998, relataram no estudo de um ano, fazendo screening antenatal em 22264 gestantes, incidência de $1 \%$ de anticorpos com potencial de desenvolvimento de doença hemolítica neonatal, sendo 70,9\% (I73/244) pertencentes ao sistema Rhesus e 29, I\% (7I/244) como pertencentes a outros sistemas mais raros, mostrando sua importância na isoimunização materna e doença hemolítica neonatal.

Nos grupos DeE(Tabela I) concentramse as incompatibilidades ao sistema $A B O, c o m$ predomínio do anticorpo anti-A sobre o anticorpo anti-B $(78,8 \%$ vs $21,2 \%$, no grupo $D$ e $82,2 \%$ vs $17,7 \%$, no grupo $E$ ).

B) Evolução clínica: $O$ mecanismo de hemólise da doença hemolítica neonatal Rh se baseia na segunda resposta à nova exposição antigênica. Ela é rápida e mediada por imunoglobulina da classe lgG. Esta imunoglobulina materna passa por mecanismos passivo e ativo, através da placenta para a circulação fetal, fixando-se nos antígenos de superfície do eritrócito fetal. A destruição dos eritrócitos se faz, principalmente, no sistema retículoendotelial e baço. Os macrófagos e monócitos possuem em suas superfícies receptores para os fragmentos Fc da imunoglobulina. Assim sendo, o eritrócito recoberto por imunoglobulinas é imediatamente fagocitado pelos macrófagos ${ }^{9}, 10$.

A gravidade da hemólise está na dependência da reação antígeno-anticorpo. Esta reação é regida por fatores relacionados à união do anticorpo com o antígeno e a aglutinação dos eritrócitos entre si. Dentre os fatores relacionados à união do anticorpo com o antígeno, temos a constante de equilíbrio, que representa a adaptação do anticorpo ao antígeno. Quanto maior a constante de equilíbrio, maior a afinidade entre eles e menos imediata a ruptura desta ligação". Outros fatores são a força iônica do meio, que afeta diretamente a taxa de associação, e o número de sítios antigênicos, quanto maior o número, maior a chance de ligação.

Entre os problemas resultantes da incompatibilidade sangüínea materno-fetal, a doença hemolítica neonatal por incompatibilidade ao sistema $A B O$ vem assumindo papel importante devido a sua incidência elevada e a diminuição da incidência da incompatibilidade Rh.

O método de prevenção para inibição da formação de anticorpos no sistema Rh é inútil para o sistema $A B O$, porque os anticorpos anti-A e anti-B têm presença natural em todos os indivíduos que não possuem os antígenos correspondentes $^{12}$.

O marcador imuno-hematológico caracterizado pelo teste de Coombs indica a presença do eritrócito provido de imunoglobulina ou complemento em sua superfície em cerca de, 
no mínimo, 150 moléculas por eritrócito ${ }^{13,14}$. A fraca positividade do teste é devido a número menor de sítios antigênicos com mais espaço entre eles e a menor quantidade de moléculas de anticorpo. O teste da eluição retira os anticorpos destes eritrócitos neonatais e os expõe ao eritrócito tipo $A B O$ de adulto, caracterizando-os melhor. A exposição a anticorpos menos intensa com conseqüente menor destruição eritrocitária leva geralmente a uma síndrome ictérica mais leve $e^{13,14}$.

Outras incompatibilidades sangüíneas materno-fetais, a de sistemas mais raros, vêm ganhando importância pelo diagnóstico, detecção destes anticorpos e sua correlação com a doença hemolítica neonatal. Os anticorpos destes sistemas geralmente não causam doença hemolítica neonatal grave pela baixa imunogenicidade de seus antígenos. Os antígenos Kell, E e c que apresentam I\% a 5\% do poder imunogênico do antígeno $D$ são responsáveis por doença hemolítica neonatal, às vezes grave. Enquanto outros antígenos destes sistemas mais raros com $0,1 \%$ do poder imunogênico do antígeno $D$, muito raramente provocam doença hemolítica grave ${ }^{5}$.

Grupo I-A: Neste grupo predominam os anticorpos do sistema Rh. Os anticorpos anti-D, isolados, foram detectados em 43/ 83 (5I,8\%); em associação com anticorpo anti-C, em I3/83 (I5,7\%); e em associação a outros anticorpos, em 5/83 (6,0\%), totalizando $61 / 83$ (73,5\%). Os anticorpos do sistema Rh, excluindo o anticorpo anti$D$, na forma isolada ou em associação com outros anticorpos, totalizam I7/83 (20,5\%), enquanto os anticorpos raros (anti-S; anti$\left.\mathrm{Jk}^{\mathrm{a}}\right)$, totalizam $2 / 83(2,4 \%)$.

Quanto à evolução clínica neonatal, os recém-nascidos com anticorpo anti-D, isolado, 10/43 (23,2\%) apresentaram icterícia precocemente; $29 / 43(67,4 \%)$, icterícia tardiamente, e $4 / 43$ (9,3\%) evoluíram com descoramento de mucosas.

Dos recém-nascidos, cujas mães apresentavam anticorpos anti-D+C, I0/13 (76,9\%) evoluíram com icterícia precoce; $3 / 13$ $(23,1 \%)$, com icterícia tardia e $3 / 13(23,1 \%)$ apresentaram-se descorados.

Dos recém-nascidos com anticorpos do sistema Rh não anti-D isolado, 15,4\% (2/I3) evoluíram com icterícia precoce; $76,9 \%$ (I0) 13), com icterícia tardia e nenhum apresentou descoramento de mucosas.
Entre os recém-nascidos com anticorpos de sistemas mais raros, houve um que evoluiu com icterícia precoce (anticorpo anti-jka $k^{a}$ e outro com icterícia tardia (anticorpo anti-S). Nenhum destes recém-nascidos apresentou descoramento de mucosas.

Grupo I-B: Neste grupo predominam também os anticorpos do sistema Rh, representados pelos anticorpos anti-D em I7/66 (25,7\%); anti-D+C, 2/66 (3,0\%) e anti-D associados a outros anticorpos em I/66 (I,5\%). Os anticorpos do sistema Rh, excluindo-se os anticorpos anti- $D$, foram detectados em 20/66 (30,3\%). Quanto aos anticorpos raros nenhum foi detectado nos recém-nascidos deste grupo. Neste grupo, 54/ $66(81,8 \%)$ recém-nascidos evoluíram com icterícia tardia e apenas 2/66 (3\%) com icterícia precoce (um dos recém-nascidos com anticorpos anti-D e o outro sem anticorpo detectado, porém na mãe foi encontrado anti-Kell). Nenhum recém-nascido deste grupo apresentou-se descorado.

Este estudo confirma que $o$ anticorpo anti$D$ permanece como causa mais comum de morbidade no período perinatal e neonatal. A sua associação com o anticorpo anti-C é causa importante de doença hemolítica neonatal. Os outros anticorpos do sistema Rh excluindo o anticorpo anti-D e os anticorpos mais raros são também causa de doença hemolítica, porém não tão importante quanto ao anticorpo anti-D.

Em nosso estudo, dos 48 recém-nascidos com anticorpos anti-D, 44 apresentaram icterícia, sendo 17 com icterícia precoce, dois destes nas primeiras quatro horas de vida, 27 com icterícia tardia. Destes 48 recém-nascidos, seis apresentaram descoramento de mucosas (Dois destes recém-nascidos em suas respectivas mães foram encontrados anticorpos anti-D +e e outro anti-C+D). Foram submetidos a tratamento 26 recém-nascidos (Tabela 4), todos, a fototerapia; quatro a uma única exsangüíneotransfusão, um a duas e um terceiro a três (Tabela 2).

Em 1998, Howard ${ }^{8}$ etal. citam o anticorpo anti-D como a principal causa de doença hemolítica neonatal. Referem que a associação anticorpo anti-D+C tem importância clínica considerável, porém segundo Bowman ${ }^{15}$, em 1991, o anticorpo anti-C isolado raramente causa doença hemolítica neonatal.

Neste estudo, o anticorpo anti-C, em associação com o anticorpo anti-D, também foi causa importante de doença hemolítica neonatal (Tabela 2). Dos oito recém-nascidos com estes anticorpos, todos evoluíram com icterícia, sendo que seis evoluíram com icterícia precoce, um dos quais com icterícia nas primeiras quatro horas de vida, dois com icterícia tardia. Dois recém-nascidos apresentaram-se descorados. Seis dos oitos recém-nascidos receberam fototerapia, três foram submetidos a uma única exsangüíneotransfusãoe um a duas.

Os anticorpos anti-E e anti-c, como os anticorpos anti-D, são freqüentes ${ }^{16}$. $O$ anticorpo anti-c é importante causa de doença hemolítica neonatal grave, às vezes apresentando clínica semelhante à do anticorpo anti$D$, com hemólise gravee, por vezes, causando colestase $^{17}$. Saint-Martin ${ }^{18}$ et al., em 199I, descreveram cinco casos com isoimunização por anti-E e anti-c, dos quais três necessitaram exsangüíneotransfusão e dois tiveram evolução letal. $\mathrm{O}$ anticorpo anti-e é comum após transfusões e pode ser causa de anemia hemolítica.

Neste estudo, aqui representado, obtivemos nove recém-nascidos com 0 anticorpo anti-c. Destes, um evoluiu com icterícia precoce e oito com icterícia tardia, sendo necessário tratamento em dois recém-nascidos (fototerapia). $O$ anticorpo anti-E foi detectado em seis recém-nascidos (cinco no grupo I e um no grupo E). No grupo I, um recém-nascido evoluiu anictérico, outro com icterícia precoce e três com icterícia tardia. 0 recém-nascido com icterícia precoce foi submetido a fototerapia e a três exsangüíneotransfusões. No grupo $E$, o recém-nascido apresentou icterícia tardia, porém sem necessidade de tratamento. Neste estudo, aqui representado, observamos também que 0 anticorpo anti-E é causa importante de doença hemolítica neonatal, necessitando inclusive de exsangüíneotransfusão. $O$ anticorpo anti-e foi detectado em um recém-nascido que evoluiu com icterícia tardia, corado e não necessitou de tratamento.

Os anticorpos do sistema Kell podem causar doença hemolítica neonatal grave. A presença do anticorpo anti-Kell no feto e, posteriormente no recém-nascido, pode levá-lo à anemia grave devido ao efeito inibitório da eritropoiese, independente da concentração do anticorpo ${ }^{8}$.

Weiner ${ }^{19}$ et al., em 1996, em estudo com 


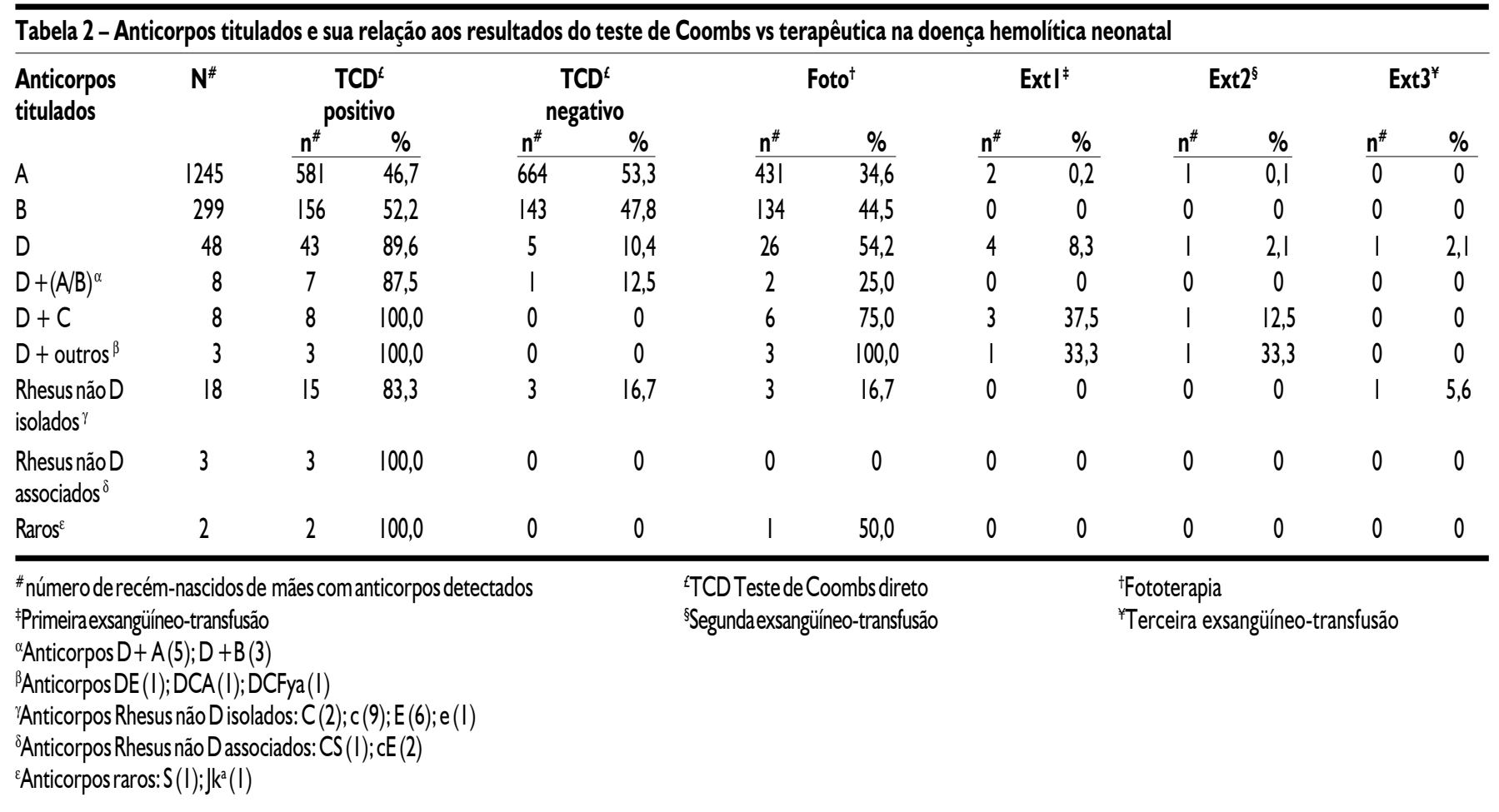

65 fetos, compararam a doença hemolítica por anti-Kell e por anti-D. Os fetos com anemia por doença hemolítica por anti-Kell apresentaram reticulócitos em níveis mais baixos e níveis de bilirrubinas comparáveis aos dos fetos anêmicos por anti-D.

Bowman ${ }^{20}$ et al., em 1992, em estudo retrospectivo com 459 gestantes e $31 \mathrm{I}$ isoimunizadas com anticorpo anti-Kell, observaram que 5\% (20/396) dos recém-nascidos apresentaram doença hemolítica. Um dos recém-nascidos evoluiu para óbito por kernicterus e três nasceram hidrópicos. Os autores relatam ainda que a doença hemolítica neonatal embora rara pode ser tão severa quanto a doença hemolítica pelo anticorpo anti-D. No entanto, existe sempre história prévia de aborto, natimorto e/ou transfusão sangüínea.

Neste estudo, aqui representado, foram detectados três anticorpos anti-Kell em sangue materno, porém ausentes nos respectivos recém-nascidos. Destes, um evoluiu com icterícia precoce e outros dois com icterícia tardia. Todos se apresentaram com mucosas coradas. Um dos recém-nascidos que evoluiu com icterícia tardia necessitou de tratamento fototerápico. Este anticorpo foi também encontrado neste estudo em associação com o anticorpo anti- $D$, no sangue materno, porém não no recém-nascido. Este evoluiu com icterícia precoce, porém não necessitou de tratamento. A ausência do anticorpo anti-Kell no sangue do recém-nascido talvez tenha configurado evolução da síndrome ictérica mais leve nestes pacientes.

Aimportância clínica imuno-hematológica do sistema Duffy está na imunogenicidade de seu antígeno Fy ${ }^{\mathrm{a}}$ com o seu anticorpo correspondente podendo causar doença hemolítica neonatal ${ }^{10}$. Este anticorpo é relativamente comum, enquanto $\mathrm{o}$ anticorpo anti- $\mathrm{Fy}^{\mathrm{b}}$ é mais raro.

Howard ${ }^{8}$ et al., em 1998, citam nove recém-nascidos com anticorpos anti-Fya, seis deles com história prévia materna de transfusão sangüínea e apenas um recém-nascido que necessitara de tratamento com fototerapia.

Filbey ${ }^{21}$ et al., em 1995, relataram 25 recém-nascidos com este anticorpo, sendo que $16 \%$ (4/25) necessitaram de fototerapia e um (4\%) foi submetido a exsangüíneotransfusão.

Neste estudo, um único anticorpo anti-Fy ${ }^{\mathrm{a}}$ foi detectado, porém associado aos anticorpos anti-C e anti-D (Tabela 2). Este paciente evoluiu com icterícia precoce, descoramento de mucosas e recebeu tratamento fototerápico, não necessitando de exsangüíneotransfusão.

Os anticorpos do sistema Kidd (anti Jk ${ }^{\mathrm{a}}$ anti-j $\left.k^{b}\right)$ são freqüentemente encontrados em baixa titulação e sua associação com outros anticorpos, como o anticorpo anti-D e/ ou anti-C é comum. A doença hemolítica neonatal ocasionalmente ocorre, mas raramente é grave.

Neste estudo, aqui representado, dos anticorpos do sistema Kidd, três anti-Jk $\mathrm{k}^{\mathrm{e}}$ um anti-Jk $\mathrm{k}^{\mathrm{b}}$, foram detectados no sangue materno e somente $o$ anticorpo anti- $\mathrm{k}^{\mathrm{a}}$, isolado, foi detectado no recém-nascido. Este evoluiu com icterícia precoce, porém com mucosas coradas e foi submetido a fototerapia apenas, - que caracteriza a pouca gravidade deste anticorpo.

No sistema MNS, os anticorpos anti-S, anti-s e anti-U podem ocasionar doença hemolítica neonatal. Filbey ${ }^{21}$ et al., em 1995, relataram que de cinco recém-nascidos com anticorpo anti-S, nenhum necessitou de tratamento.

Howard ${ }^{8}$ et al., em 1998, relataram que dez recém-nascidos com anticorpo anti-S, três com história prévia materna de transfusão sangüínea, nenhum necessitou de tratamento.

Neste estudo, o anticorpo anti-S foi detectado em três mães. Apenas um recém-nascido apresentou o anticorpo anti-S. Ele evoluiu com icterícia tardia, corado, mas também não ne- 
cessitou de tratamento. Os anticorpos anti-M detectados em 18 mães não foram encontrados nos respectivos recém-nascidos. Cinco destes evoluíram anictéricos, 13 com icterícia tardia, sendo apenas dois submetidos à fototerapia.

No Grupo $D$ do estudo há predomínio do anticorpo anti-A em 580/736 (78,8\%) em relação ao anticorpo anti-B, I56/736 (21.2\%). Quanto à evolução clínica neonatal, dos recém-nascidos com anticorpos anti-A, 97/580 $(16,7 \%)$ evoluíram com icterícia precoce e $395 / 580(68,1 \%)$, com icterícia tardia. Nenhum evoluiu com descoramento de mucosas. Os recém-nascidos com anticorpos anti-B, 40/156 (25,6\%) evoluíram com icterícia precoce e 97/156 (62,2\%) com icterícia tardia. Em um paciente foi observado descoramento de mucosas. Neste grupo (D), 43,6\% (253/580) dos recém-nascidos com anticorpo anti-A receberam tratamento e nos recém-nascidos com anticorpo anti-B, 74/I56 (47,4\%). Apesar da aparente diferença percentual entre eles, não houve diferença estatística.

No geral, dos recém-nascidos deste grupo, I37/736 (18,6\%) evoluíram com icterícia precoce e 492/736 (66,8\%) com icterícia tardia e quase a totalidade apresentou-se corado clinicamente. Aincidência de tratamento foi de $327 / 736$ (44,4\%). Dois recém-nascidos necessitaram de exsangüíneotransfusão, um uma única e o outro, duas.

No grupo $E$, o predomínio do anticorpo anti-A foi de 663/807 (82, I\%) em relação ao anticorpo anti-B, com I43/807 (I7,7\%). Foi também encontrado neste grupo um anticorpo pertencente ao sistema Rhesus, anticorpo anti-E, com incidência de $0,1 \%$. Quanto à evolução clínica neonatal, dos recém-nascidos com anticorpos anti-A, 49/663 (7,4\%) evoluíram com icterícia precoce e 48I/ 663 (72,5\%) com icterícia tardia. Todos os recém-nascidos evoluíram com as mucosas coradas.

Neste grupo, 176/663 (26,5\%) dos recém-nascidos com anticorpos anti-A necessitaram de tratamento, enquanto os recémnascidos com anticorpo anti-B, 60/143 (42,0\%). Adiferença entre os dois anticorpos, neste grupo, foi significante.

No geral, os recém-nascidos do grupo $E$, 70/807 (8,7\%), evoluíram com icterícia precoce, 579/807 (7I,7\%), com icterícia tardia e todos se apresentaram corados clinicamente. A incidência de tratamento foi de 236/807 $(29,2 \%)$. Um recém-nascido necessitou de uma única exsangüíneotransfusão.

C) Tratamento: No grupo I-A, dos recémnascidos com anticorpos anti- $D$, isoladamente, 20/43 (46,5\%) necessitaram de tratamento (fototerapia e/ou exsangüíneotransfusão), enquanto os recém-nascidos com anticorpos anti-D+C, I I/I3 (84,6\%), necessitaram de tratamento. Apesar da diferença percentual, estatisticamente não foi significante, provavelmente pelo tamanho da amostra.

Neste grupo dos recém-nascidos que necessitaram de tratamento (fototerapia e/ou exsangüíneotransfusão), 20/83 (24, I\%) apresentaram o anticorpo anti-D isolado; II/83 $(13,2 \%)$ anti-D+C; $3 / 83$ (3,6\%) anticorpos do sistema Rh não anti-D; e I/83 (I,2\%) anticorpos raros $\left(a n t i-J k^{a}\right)$. É neste grupo também que se concentrou o maior número de casos submetidos a exsangüíneotransfusão, $7 /$ $83(8,4 \%)$ dos recém-nascidos foram submetidos a uma única exsangüíneotransfusão; $3 / 83$ (3,6\%) a duas; e 2/83 (2,4\%) a três. Os níveis de bilirrubinas, tanto totais quanto indiretas, estão sempre aumentados em relação aos imediatamente anteriores à exsangüíneotransfusão caracterizando o efeito rebote destes casos.

Nos casos de necessidade de tratamento no grupo I-B, a terapêutica indicada foi a fototerapia em 9/66 (13,6\%) dos recém-nascidos. Destes, 4/66 (6,1\%) apresentavam anticorpos anti-D; I/66 (I,5\%) do sistema Rh não anti-D; e 4/66 (6, I\%) tiveram detectado nas mães respectivas anticorpos raros (anti-Jk', anti-K, anti-M), porém não encontrados neles. Nenhum recém-nascido deste grupo foi submetido a exsangüíneotransfusão.

Comparativamente, os grupos I-A e I$B$ apresentaram níveis de bilirrubinas indiretas indicativos de tratamento fototerápico com intervalos de confiança sobrepostos I-A IC95\%[7,4 - 9,6] vs I-B IC95\%[5,6 - I4,8] com $P=0,309$, não estatisticamente significante. Os níveis de hemoglobina e de hematócrito, na ocasião da indicação do tratamento, também não mostraram diferenças estatisticamente significantes (intervalos de confiança sobrepostos hemoglobina I-A IC95\% [I3,0 $-15,6]$ vs I-B IC95\% [I4,0-I7,8], P = 0,478 e hematócrito I-A IC $95 \%[38,8-$
$46,0]$ vs I-B IC95\% $[43,6-49,8], P=$ 0,500 .)

A porcentagem de tratamento do grupo IA foi de $49,4 \%(4 \mathrm{I} / 83)$ e do grupo I-B de $13,6 \%(9 / 66)$ e, apesar da diferença percentual, o cálculo do $\mathrm{P}=0,057$ mostrou-se não significante provavelmente pela amostra ser relativamente pequena.

No grupo I deste estudo, dos 48 recém-nascidos com anticorpo anti-D, 26 deles foram submetidos à fototerapia, e seis a exsangüíneotransfusão, sendo que quatro, a uma única, outro, a duas e um terceiro, a três (Tabela 2).

Dos recém-nascidos anticorpos anti$D+C$ deste grupo, seis dos oito receberam fototerapia, três foram submetidos a uma única exsangüíneotransfusão e um a duas.

Dos recém-nascidos com anticorpos antiEdetectados neste trabalho, apenas um necessitou de tratamento fototerápico e também foi submetido a três exsangüíneo-transfusões, gravidade também observada por SaintMartin $^{18}$ et al., em 1991.

Em relação ao anticorpo anti-c detectados em nove dos recém-nascidos de nosso estudo, apenas dois pacientes foram submetidos a tratamento fototerápico, um dos quais com evolução precoce da icterícia, o que contradiz os dados da literatura quanto a maior gravidade deste anticorpo.

Orecém-nascido com anticorpo anti-e do grupo de estudo aqui representado evoluiu com icterícia tardia, mucosas coradas e não necessitou de qualquer tratamento.

Em relação ao sistema Kell, nos recémnascidos deste estudo, em nenhum se detectou este anticorpo, talvez seja este o motivo da sua evolução benigna.

Quanto ao anticorpo anti-Fy detectado em associação com anticorpos anti-C eanti-D, em nosso estudo o tratamento foi apenas com fototerapia, não necessitando de exsangüíneotransfusão, semelhantes aos achados por Filbey ${ }^{21}$ et al., em 1995 e Howard $^{8}$ et al., 1998.

Dos recém-nascidos com anticorpos do sistema Kidd, apenas o anticorpo anti-Jka foi detectado no recém-nascido, que evoluiu com icterícia precoce e necessitou de tratamento fototerápico.

Simpson ${ }^{25}$ et al. relataram em 1977 o aparecimento do anticorpo anti-Jk $\mathrm{k}^{\mathrm{a}} \mathrm{em}$ paciente de 19 anos, secundigesta. Durante esta segunda gravidez, por incompatibilida- 
Tabela 3 - Risco relativo para o tratamento com fototerapia segundo os grupos de estudo do estudo de prevalência de marcadores imuno-hematológicos para doença hemolítica neonatal

\begin{tabular}{|c|c|c|c|c|}
\hline Grupos de estudo & $n_{f} / n_{t}^{*}$ & $\%$ & Risco relativo & IC95\%RR $^{\&}$ \\
\hline$\overline{I-A}$ & $41 / 83$ & 49,40 & 3,62 & $1,90<R R<6,90$ \\
\hline I-B & $9 / 66$ & 13,64 & 1,00 & ref. \\
\hline D & $327 / 736$ & 44,43 & 3,26 & $|, 77<R R<6,0|$ \\
\hline$E$ & $236 / 807$ & 29,24 & 2,14 & $1,16<R R<3,97$ \\
\hline
\end{tabular}

*número de recém-nascidos sob fototerapia/número total por grupo

\&|C95\%RRintervalo de confiança de $95 \%$ do risco relativo

$\mathrm{n} / \mathrm{n}$ : númerode recém-nascidos submetidos afototerapia/número total derecém-nascidos

ref.: categoria dereferência

Tabela 4 - Risco relativo para o tratamento com exsangüíneotransfusão segundo os grupos de estudo do estudo de prevalência de marcadores imuno-hematológicos para doença hemolítica neonatal

\begin{tabular}{|c|c|c|c|c|c|}
\hline Grupos de Estudo & I EXT n $/ \mathrm{ent}(\%)$ & $\mathbf{R R}^{\dagger}($ IC 95\%) & 2 EXT n $/ \mathrm{ent}(\%)$ & $\mathbf{R R}^{\dagger}(\mathrm{IC} 95 \%)$ & 3 EXT $n_{e} / n t(\%)$ \\
\hline I-A & $77 / 83(8,43)$ & $\overline{68,06(8,48-546,48)}$ & $3 / 83(3,61)$ & $\overline{26,60(2,80-252,85)}$ & $2 / 83(3,40)$ \\
\hline I-B & - & - & - & - & - \\
\hline D & $1 / 736(0,14)$ & $1,16(0,07-17,50)$ & $1 / 736(0,14)$ & ref. & - \\
\hline $\mathrm{E}$ & $\mathrm{I} / 807(0,12)$ & ref. & - & - & - \\
\hline
\end{tabular}

${ }^{\dagger}$ RRRisco relativo

†IC95\% intervalo de confiança de $95 \%$ para risco relativo

$\mathrm{n} /$ ntnúmerode recém-nascidos submetidosa exsangüíneotransfusão/ número total de recém-nascidos

ref.: categoria de referência

de materno-fetal Rh, a gestante necessitou fazer transfusão intra-uterina por duas vezes, intercaladas por amniocentese. Por conseguinte, houve $o$ aparecimento do segundo anticorpo, anti-Jk $\mathrm{k}^{\mathrm{a}}$, com título de $\mathrm{I} / 4$. $O$ recém-nascido necessitou de quatro exsangüíneo-transfusões, mas evoluiu sem evidências de déficits neurológicos.

Nos estudos de Filbey ${ }^{21}$ et al., em 1995, em oito recém-nascidos foram detectados 0 anticorpo anti-Jka. Três pacientes necessitaram de tratamento com fototerapia, porém dois deles apresentavam concomitantemente incompatibilidade ao sistema $A B O$.

No sistema MNS, os anticorpos anti-S, anti-s e anti-U podem ocasionar doença hemolítica neonatal. Filbey ${ }^{21}$ et al., em 1995 , relataram que de cinco recém-nascidos com anticorpos anti-S nenhum necessitou de tratamento.

Howard ${ }^{8}$ et al., em 1998, relataram que de dez recém-nascidos com este anticorpo, três apresentavam história prévia materna de transfusão sangüínea, mas nenhum necessitou de tratamento.

Neste trabalho, apenas o anticorpo anti-S foi detectado em um recém-nascido, porém sem repercussão, pois também não necessitou de tratamento.

A doença hemolítica neonatal, causada pela incompatibilidade ao sistema $A B O$, resulta da interação de anticorpos maternos anti-A e/ou anti-B com os antígenos correspondentes nos eritrócitos neonatais. Embora, esta isoimunização seja mais comum, tem caráter benigno, pois raramente é grave, excepcionalmente provoca anemia e na literatura só há descrição de quatro casos de hidropsia por isoimunização $A B O^{26,10}$.

Nogrupo $D$, a incidência de tratamento foi de $44,4 \%$ (327/736) e dois recém-nascidos foram submetidos a exsangüíneotransfusão, um a uma única e outro, a duas.

No grupo $E$, a incidência de tratamento foi de 29,2\% (236/807) e um dos recém-nascidos foi submetido a única exsangüíneotransfusão.

Comparativamente, os grupos De Eapresentaram níveis de bilirrubinas indiretas indicativos de tratamento com fototerapia com intervalos sobrepostos (D) IC95\% [9,5-10,2] e (E) IC $95 \%[10,0-10,8]$, com $P=0,083$, não estatisticamente significante.

Os níveis de hemoglobina e hematócrito, na ocasião da indicação do tratamento, foram significativos $(P<0,00 \mathrm{I})$ com intervalos não sobrepostos: hemoglobina (D) IC95\% [I5, I - I5,7] vs (E) IC95\% [16,0 - I6,8] e hematócrito (D) IC95\% $[45,2-46,8]$ vs (E) IC95\% [47,9-50,5].

Neste estudo, comparando os anticorpos titulados em recém-nascidos em relação aos anticorpos do sistema Rhesus não $D$, analisando o risco para fototerapia, encontramos o anticorpo anti-D com risco de 3,25 vezes maior. O anticorpo anti-D em associação com outros anticorpos eleva para 3,47 este risco e os anticorpos anti-A e anti-B mostraram risco de 2,08 e 2,69 vezes maior.

O risco relativo para o tratamento com fototerapia, segundo os grupos de estudo ( $\mathrm{Ta}$ bela 3), mostrou que os grupos de maior risco foram o grupol-A e o grupo $D$, com valores de 3,62 e 3,26 , respectivamente. $O$ grupo $E$ mostrou um valor intermediário de 2, I 4 e o grupo de menor risco foi o grupo I-B com risco de I,00. Esta diferença confirma a maior imunogenicidade dos antígenos $D$ em relação aos outros. $O$ grupo $D$ tem risco maior em relação ao grupo E provavelmente pelo maior número de anticorpos detectáveis em relação a grupo $E$. 
Quanto ao risco relativo para tratamento com exsangüíneotransfusão (Tabela 4), segundo os grupos de estudo, observamos que: 0 grupo com maior risco de realizar até três exsangüíneo-transfusões foi ol-A. O segundo grupo de maior risco para realização de até duas exsangüíneo-transfusões foi o grupo $D .0$ terceiro grupo de risco para a realização e uma exsangüíneotransfusão foi o grupo $E$, sendo que 0 grupo I-B não realizou nenhuma exsangüíneotransfusão.

Comparando o grupo de estudo com os trabalhos de Filbey ${ }^{21}$ et al., 1995, em relação à fototerapia, observamos não haver diferença significante entre os anticorpos anti-D; anti$D+C$; anti-D+outros; anti-Rh-D isolado; anti-Rh-D associados e anticorpos mais raros. Comparando o grupo de estudo com os trabaIhos de Filbey 21 et al., 1995, em relação a exsangüíneotransfusão, observamos não haver diferença significante entre os anticorpos anti-D; anti-D+C; anti-D+outros; anti-Rh-D isolado; anti-Rh-D associados e anticorpos mais raros.

O risco relativo do recém-nascido com incompatibilidade ao anticorpo anti-D, isolado ou associado a outro anticorpo, de necessitar de fototerapia é de 3,25 e 3,47 vezes maior em relação a incompatibilidade a anticorpo Rhesus não anti-D. Comparando o anticorpo anti-B, é de 2,69 vezes e o anticorpo anti-A, 2,08 vezes maior.

$\mathrm{Na}$ cronologia do tratamento, observamos que a média de início da terapêutica foi entre o primeiro e o segundo dia de vida. No grupo do estudo, a icterícia neonatal precoce incidiu em 14,1\% (239/1692) e a icterícia tardia em 69,3\% (II72/1692) e por isso a média em horas para início do tratamento foi de 40,2.

O tempo médio de vidaà alta hospitalar foi de quatro dias, às vezes excedendo este tempo em média de mais três dias. Na rotina do Hospital e Maternidade Santa Joana, recémnascidos de parto cesárea recebem alta hospitalar em média com 60 horas de vida. Com estes valores, observamos a importante morbidade da doença hemolítica neonatal como causa da prorrogação de internação destes recém-nascidos.

Os níveis de bilirrubinas indiretas à alta hospitalar foram sempre inferiores a dois pontos do indicativo de tratamento, segundo as normas de icterícia daquele ser- viço. Dos recém-nascidos que não foram submetidos a qualquer tratamento, $16,9 \%$ (286/1692) apresentaram-se anictéricos e $46,9 \%$ (793/1692) apresentaram icterícias mensuradas de acordo com as zonas de Kramer, sendo que 45,9\% (776/I692) apresentavam-se ictéricos entre as zonas I e III de Kramer.

\section{Conclusões}

Concluímos que a prevalência geral de marcadores imuno-hematológicos associados à doença hemolítica nesta população foi de 9,07\% (32/2/35429), a incidência de doença hemolítica nos grupos estudados foi de $36,23 \%$ (6/3/1692). O grupo com teste de Coombs positivo, onde se concentram as incompatibilidades $A B O$, teve incidência de doença hemolítica superior aos demais grupos e teve também maior incidência de tratamento com fototerapia. O grupo com teste de Coombs indireto e direto positivos, onde se concentraram as incompatibilidades Rh, apresentou maior incidência de tratamento com exsangüíneotransfusão nos recém-nascidos em relação aos demais grupos.

\section{SUMMARY}

Prevalence of immunohematologic TESTS AT BIRTH AND THE INCIDENCE OF HEMOLYTIC DISEASE IN THE NEWBORN

The administration of anti-D globulin to the mothers has decreased the incidence of $R h$ hemolytic disease but the improvement of technologic assays has made it possible to identify several hemolytics diseases of the newborn.

BACKGROUND. To identify the prevalence of immunohematologic tests demonstrated by indirect (IC), direct (DC) and elution tests; to identify the incidence of hemolytic disease and its treatment (phototherapy and/or exchange transfusion) in neonates with hemolytic disease. This is a retrospective cohort-study performed

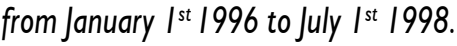

METHODS. This is a descriptive study of the immunohematologic profile of 1698 mothers and their offsprings, as risk factors for developing hemolytic disease. The inclusion criteria were the positivity of the indirect (IC) and direct (DC) Coombs tests and elution tests. Based on the inclusion criteria three group of infants were analyzed: Group I was composed of 149 offsprings of Coombs- positive mothers $(I C+)$ with antibodies associated with neonatal hemolytic disease. This group was further divided into two groups: Group I-A $(I C+D C+)$ was composed of 83 Coombs-positive offsprings (DC+) of Coombs-positive mothers (IC+) and Group I$B(I C+D C-)$ was composed of 66 Coombsnegative offsprings (DC-) of Coombs-positive mothers (IC+); Group D was composed of 736 Coombs-positive offspring's of Coombsnegative mothers (IC-); and Group $E$ was composed of 807 Coombs-negative and elution-positive offspring's of Coombsnegative mothers.

RESULTS. This study shown that the overall prevalence of immunohematologic tests associated with hemolytic disease was $9.07 \%$ (32/2/35429), 0.43\% (154/35429) among offsprings of Coombs-positive mothers, $4.10 \%$ (I453/35429) among Coombspositive infants, and $4.53 \%$ (1605/35429) among elution-positive infants. The overall incidence of hemolytic disease was $36.23 \%$ (6/3/1692), 33.56\% (50/149) among offspring's of Coombs-positive mothers, 44.43\% (327/736) among Coombs-positive infants, and $29.24 \%$ (236/807) among elution-positive infants. The overall incidence of phototherapy among infants with hemolytic disease was $36.23 \%$ (6/3/1692), $49.40 \%$ (4I/83) in group I-A (IC+DC+), I3.64\% (9/ 66) in group $I-B(I C+D C-), 44.43 \%(327 \mid$ 736 ) in group $D$, and $29.24 \%(236 / 807)$ in group $E$. The overall incidence of exchange transfusion among infants with hemolytic disease was $0.88 \%$ (15/I692), I4.46\% (I2/ $83)$ in group $I-A(I C+D C+), 0 \%(0 / 66)$ in group I- $B(I C+D C-), 0.27 \%(2 / 736)$ in group $D$, and $0.12 \%(1 / 807)$ in group $E$.

Conclusions. The results of this study allowed us to conclude that the overall prevalence of immunohematologic tests associated with hemolytic disease was $9.07 \%$ (32/2/35429) and the overall incidence of hemolytic disease was $36.23 \%(6 / 3 / 1692)$ in this study-group. The highest incidences of hemolytic disease and phototherapy were observed among Coombs-positive offsprings of Coombs-positive mothers. [RevAssoc Med Bras 2003; 49(I): 45-53]

KEYwORDS: Jaundice neonatal epidemiology. Immunohematologic tests. Phototherapy. Exchange transfusion. Coombs tests/methods. 


\section{RefERÊNCIAS}

I. Gollin YG, Copel JA. Management of the Rhsensitized mother. Clin Perinatol 1995; 22:545-59.

2. Solola A, Sibai B, Mason JM. Irregular antibodies: an assessment of routine prenatal screnning. Obstet Gynecol 1 983; 61:25-30.

3. Murray JC, Karp LE, Williamson RA, Cheng EY, Luthy DA. Rh isoimmunization related to amniocentesis. Am J Med Genet 1983; 16:527-34.

4. DeVrijer B, Harthoorn-Lasthuizen EJ, Oosterbaan HP. The incidence of irregular antibodies in pregnancy: a prospective study in the region of the 's-Hertogenbosch. Ned Tijdschr Geneeskd I999; I 43:2523-7. [Resumo].

5. Zipursky A, Bowman JM. Isoimune hemolytic diseases. In: Nathan DG, Oski FA. Hematology of infancy and childhood. 4th ed. Philadelphia:W.B. Saunders; 1993. p.44-73.

6. Schroeder ML, Rayner HL. Red cell, platelet and white cell antigens. In: Lee GR, Bithell TC, Foerster J, Athens JW, Lukens JN. Wintrobe's clinical hematology. 9th ed. Philadelphia: Lea and Febiger; 1993. p.616-46.

7. OzolekJÄ, WatchkoJF, Mimouni F. Prevalence and lack of clinical significance of blood group incompatibility in mothers with blood type A or B. J Pediatr 1994; | 25:87-9|.

8. Howard H, Martlew V, Mcfadyen I, Martlew W, Mc Fadgen I, Clarke C, et al. Consequences for fetus and neonate of maternal red cell alloimmunisation. Arch Dis Child 1998; 78:62-6.

9. Zipursky A. Mechanism of hemolysis. Mead Johnson Symp. Perinat. Dev Med 1 982; 19: 17-24.

10. Wirthner D, Hohlfeld P, Tissot JD. Maladie hémolytique périnatale. Ire partie: physio- pathologie. J Gynecol Obstet Biol Reprod 1998; 27:135-43.

II. Weatherall DJ, Bunch C. O sangue e os órgãos hematopoéticos. In: Smith LH Jr, Thier SO. Fisiopatologia: os princípios biológicos da doença. 2a ed. São Paulo: Editora Médica Panamericana; 1990. p. 158-294.

12. Grundbacher FJ. The etiology of $A B O$ hemolytic disease of the newborn. Transfusion. 1980; 20:563-8.

13. Romano EL, Hughes-Jones NC, Mollison PL. Direct antiglobulin reaction in $\mathrm{ABO}$-haemolytic disease of the newborn. Br Med J 1973; 1:524-6.

14. Matsunaga AT, Lubin B.H. Hemolytic anemia in the newborn. Clin Perinatol 1995; 22:803-35.

15. Bowman JM, PollockJM, Peterson LE, Harman CR, Manning FA, Menticoglou SM. Fetomaternal hemorrhage following funipuncture: increase in severity of maternal red-cell alloimmunization. Obstet Gynecol I 994; 84:839-43.

16. Shirey RS, Edwards RE, Ness PM. The risk of alloimmunization to c (Rh4) in RIRI patients who presents with anti-E. Transfusion. 1994; 34:756-8.

17. Monteiro MAG, Ferfebaum R, Diniz EMA. Aspectos imuno-hematológicos, genéticos e clínicos da aloimunização por anticorpo anti-c: relato de dois casos. Pediatria (São Paulo) 1996; 18:95-8.

18. Saint-Martin J, Cabantous A, Choulot JJ, Mensire A. Pour une meilleure prévention des alloimmunisations anti-érythrocytaires (anti-E et anti-c). J Gynecol Obstet Biol Reprod 199I; 20:745-6

19. Weiner CP, Widness JA. Decreased fetal erythropoieses and hemolysis in kell hemolytic anemia. AmJ Obstet Gynecol 1996; 174:547-5 I.
20. Bowman JM, PollockJM, Manning FA, Harman CR, Menticoglou S. Maternal kell blood group alloimmunization. Obstet Gynecol 1992; 79:239-44.

21. Filbey D, Hanson U, Wesstrom G. The prevalence of red cell antibodies in pregnancy correlated to the outcome of the newborn: a 12 year study in central Sweden. Acta Obstet Gynecol Scand I 995; 74:687-92.

22. Linn S, Schoenbaum SC, Monson RR, Rosner B, Stubblefield PG, Ryan KJ. Epidemiology of neonatal hyperbilirubinemia. Pediatrics 1985; 75:70-4.

23. Horiguchi T, Bauer C. Ethnic differences in neonatal jaundice: comparison of japanese and Caucasian newborn infants. Am J Obstet Gynecol 1975; 121:71-4.

24. Maisels MJ, Newman TB. Jaundice in fullterm and near-term babies who leave the hospital within 36 hours. Clin Perinatol 1998; 25:295-302.

25. Simpson MB, Pryzbylik JÁ, Denham MA, Radcliffe JH. Appearance of maternal anti-Jka antibody following intrauterine transfusions and amniocentesis. Obstet Gynecol 1978; 52: 616-7.

26. Foerster J. Alloimune hemolytic anemias. In: Lee GR, Bithell TC, Foerster J, Athens JN, Lukens JN. Wintrobe's clinical hematology. 9th ed. Philadelphia: Lea and Febiger; 1993. p.II46-69.

Artigo recebido: 10/10/2001 Aceito para publicação: 29/08/2002 